\title{
Avaliação clínica e radiográfica do tratamento endodôntico em sessão única de dentes com lesões periapicais crônicas
}

\section{Clinic and radiographic evaluation of one-appointment root canal therapy in teeth with chronic periapical lesions}

\author{
Janir Alves SOARES* \\ Carlos Augusto Santos CÉSAR*
}

\begin{abstract}
SOARES, J. A.; CÉSAR, C. A. S. Avaliação clínica e radiográfica do tratamento endodôntico em sessão única de dentes com lesões periapicais crônicas. Pesqui Odontol Bras, v. 15, n. 2, p. 138-144, abr./jun. 2001.

Este estudo teve como objetivo avaliar a incidência de dor pós-operatória e o tipo de reparação periapical, após tratamento endodôntico em sessão única, em pacientes portadores de polpa necrótica associada a áreas radiolúcidas periapicais, assintomáticos. Para tanto, após o preparo biomecânico empregando-se a técnica "step down" seguido por "step back", auxiliada por copiosa irrigação com solução de hipoclorito de sódio a 5,0\%, procedeu-se à obturação dos canais radiculares pela técnica convencional, utilizando-se cones de guta-percha e cimento à base de óxido de zinco e eugenol. No pós-operatório imediato, $16,6 \%$ dos pacientes apresentaram dor espontânea, contudo a incidência de dor do tipo severa - "flare-ups" foi da ordem de 3,3\%. Aos doze meses, todos os pacientes estavam assintomáticos e sem fístulas, todavia, apenas $46,4 \%$ apresentaram completa resolução das áreas radiolúcidas periapicais. Portanto, a médio prazo, o tratamento endodôntico em sessão única proporcionou $100 \%$ de sucesso clínico, mas reduzido percentual de sucesso radiográfico.
\end{abstract}

UNITERMOS: Tratamento do canal radicular; Doenças periapicais.

\section{INTRODUÇÃO}

A microbiota distribuída pelo sistema de canais radiculares dos dentes com polpa necrótica representa potente fonte antigênica mantenedora da destruição do parênquima periapical, por vezes determinando agudizações: um quadro clínico/patológico caracterizado localmente por dor, edema e/ou exsudação. Ademais, essas duas entidades biológicas, distintas e complexas, a microbiota endodôntica e a lesão periapical crônica, influenciam significativamente o prognóstico dos tratamentos endodônticos ${ }^{8,12,23,24}$. Por conseguinte, numa concepção biológica, quando do tratamento endodôntico de pacientes portadores de patologias periapicais em sessão única, dois fatores de significativa importância clínica causam questionamentos: a incidência de dor pós-operatória e a qualidade da reparação periapical ${ }^{2,11,22,31}$.

O preparo biomecânico configura-se como uma das fases mais importantes no controle da infecção endodôntica ${ }^{24}$, pois a ação de corte e de remoção de tecidos, auferida pelos instrumentos, associada ao fluxo do irrigante e à sua ação antimicrobiana, é capaz de alterar, significativamente, a microbiota, situada no canal radicular principal e a poucos micrômetros da dentina circuncanalicular. No entanto, devido à natureza difusa da infecção endodôntica pelos istmos, túbulos dentinários, canais secundários e acessórios, cementoclastos apicais e áreas de reabsorção cementária apical ${ }^{8,12,24}$, o preparo biomecânico e a imediata obturação do canal radicular deixam dúvidas sobre a qualidade do saneamento obtido. Possivelmente, alguns relatos de lesão periapical refratária ou muitos casos de áreas radiolúcidas parcialmente reparadas sejam decorrentes dessa infecção remanescente. Não obstante, a literatura endodôntica relata plausíveis resultados de dentes com polpa necrótica e radiolucidez periapical, tratados em sessão única; muitos dos quais num intervalo de tempo relativamente curto $^{1,3,15,17,21}$. Assim, propusemos avaliar dois aspectos de relevante importância clínica à saúde dos pacientes: a incidência de dor pós-operatória e a qualidade da reparação periapical, após

\footnotetext{
* Professores da Disciplina de Endodontia da Faculdade Federal de Odontologia de Diamantina - Minas Gerais e Doutorandos em Endodontia pela Faculdade de Odontologia de Araraquara da UNESP.
} 
SOARES, J. A.; CÉSAR, C. A. S. Avaliação clínica e radiográfica do tratamento endodôntico em sessão única de dentes com lesões periapicais crônicas. Pesqui Odontol Bras, v. 15, n. 2, p. 138-144, abr./jun. 2001.

tratamento endodôntico de dentes com lesão periapical crônica, em sessão única.

\section{PACIENTES E MÉTODOS}

Participaram deste estudo pacientes encaminhados à clínica de Endodontia da Faculdade Federal de Odontologia de Diamantina - MG. Após aprovação do projeto de pesquisa pela COPE/FAFEOD, os pacientes selecionados foram devidamente esclarecidos do propósito deste estudo clínico e assinaram documento de consentimento informado livre e esclarecido. A seleção dos pacientes constou dos seguintes passos: 1) anamnese, 2) exame clínico extra- e intrabucal, 3) testes de sensibilidade pulpar e 4) avaliação radiográfica periapical. Clinicamente, todos os pacientes estavam assintomáticos, as coroas dentárias apresentavam favoráveis condições ao isolamento absoluto e ulterior retenção de adequada restauração coronária.

Foram excluídos: 1) elementos dentários com doença periodontal avançada ou lesão combinada endoperiodontal; 2) pacientes usuários de medicamentos analgésicos/antiinflamatórios, antibióticos ou imunossupressores e 3) casos de retratamentos endodônticos.

A amostragem ficou constituída por 27 pacientes, com idade variando de 19 a 54 anos $( \pm 29,5$ anos), perfazendo um total de trinta dentes, anteriores e pré-molares, com diagnóstico de necrose pulpar associada à definida área radiolúcida periapical, apresentando dimensão mínima de, aproximadamente, dez milímetros no seu maior diâmetro.

Os procedimentos clínicos foram realizados por um único operador (J.A.S.). Destarte, após isolamento absoluto, anti-sepsia do campo operatório e abertura coronária, neutralizou-se o conteúdo tóxico/séptico pulpar, no sentido coroa/ápice, empregando-se limas tipo Kerr de pequeno diâmetro: $\mathrm{n}^{\circ}$ 08, 10 ou 15, mediante copiosa irrigação com solução de hipoclorito de sódio a 5,0\%. Em prosseguimento, efetuou-se o preparo biomecânico pela técnica híbrida de instrumentação - "step down" seguido de "step back". Assim, após a aplicação de cada lima ou broca Gates-Glidden, irrigou-se o canal radicular com $3 \mathrm{ml}$ de solução de hipoclorito de sódio a 5,0\%. O batente apical correspondeu, no mínimo, ao instrumento memória $\mathrm{n}^{\circ} 35$ e ficou situado a aproximadamente $1 \mathrm{~mm}$ aquém do ápice radiográfico. Manteve-se o forame patente e, após remoção da camada residual, irrigaram-se os ca- nais radiculares com $5 \mathrm{ml}$ de soro fisiológico esterilizado, obtendo-se em seguida amostras microbiológicas que foram transferidas para os meios de cultura caldo infusão cérebro/coração (BHI) e tioglicolato, com incubação aeróbia e microaerófila. $\mathrm{Na}$ obturação dos canais radiculares, empregaram-se cones de guta-percha (Dentsply Indústria e Comércio Ltda., Petrópolis, RJ - Brasil) e cimento Fillcanal (DG Ligas Odontológicas Ltda., Catumbi, São Paulo - Brasil), pela técnica da condensação lateral ativa.

Dentre as informações prestadas aos pacientes, relatou-se a possibilidade de dor pós-operatória, os quais foram orientados a informar-nos sobre o seu início, bem como a duração da mesma após imediato enfoque terapêutico. Com relação à sua intensidade, a dor foi classificada em três niveis, em função do que se instituiu um protocolo terapêutico: A - dor leve (não requereu uso de medicação analgésica); B - dor moderada (controlada pelo uso de salicilatos ou paracetamol) e C - dor severa (tratada com analgésicos/antiinflamatórios derivados dos ácidos heteroaril-acético e aril-propiônico, associados à antibióticos a base de fenoximetilpenicilina).

Trimestralmente, os pacientes foram reavaliados clínica e radiograficamente e, ao final de 12 meses, quatro docentes calibrados interpretaram, individualmente, as radiografias para diagnóstico e proservação, nas seguintes categorias: A - lesão periapical completamente reparada - caracterizada por total resolução óssea, podendo estar associada à: espaço periodontal normal com lâmina dura circundando o ápice; ausência de espaço periodontal e/ou lâmina dura ou ligeiro espessamento, delimitando a região do forame apical ou residual, material obturador extravasado; B - lesão periapical parcialmente reparada - apresentando espaço periodontal ampliado, no mínimo duas vezes maior que o normal e C - lesão periapical estacionária ou em crescimento - ausência de reparo. Somente foram considerados sucessos os tratamentos que apresentaram completa reparação periapical, associados à ausência de sinais e sintomas endodônticos.

\section{RESULTADOS}

Após o preparo biomecânico, 28 dentes (93,3\%) estavam microbiologicamente negativos. Cinco pacientes $(16,6 \%)$ relataram dor pós-operatória, sendo dois $(6,6 \%)$ com sintomatologia leve ou moderada e um $(3,3 \%)$ com dor severa. Onze dentes 
SOARES, J. A.; CÉSAR, C. A. S. Avaliação clínica e radiográfica do tratamento endodôntico em sessão única de dentes com lesões periapicais crônicas. Pesqui Odontol Bras, v. 15, n. 2, p. 138-144, abr./jun. 2001.

TABELA 1 - Tipos de reparação periapical e respectivas condições microbiológicas dos canais radiculares no momento da obturação $(n=28)$.

\begin{tabular}{l|c|c|c|c}
\hline \hline \multirow{2}{*}{$\begin{array}{c}\text { Cultura } \\
\text { microbiológica }\end{array}$} & \multicolumn{3}{c|}{ Reparação } & \multirow{2}{*}{ Total } \\
\cline { 2 - 5 } & Completa & Parcial & Ausente & \\
\hline Positiva & - & 2 & 2 & 4 \\
\hline Negativa & 13 & 11 & - & 24 \\
\hline Total & 13 & 13 & 2 & 28 \\
\hline \hline
\end{tabular}

estavam com a obturação exata e 19 obturados ligeiramente aquém do ápice radiográfico. Não se verificou associação entre os tipos de dor pós-operatória e as variáveis: término apical das obturações e condição microbiológica dos canais radiculares após o preparo biomecânico. Dos vinte e oito tratamentos acompanhados clínica e radiograficamente, aos 12 meses, 13 (46,4\%) estavam totalmente ou parcialmente reparados, conforme mostra a Tabela 1. A cultura microbiológica negativa não influenciou no tipo de reparo periapical (Tabela 1). Ademais, não se observou notável diferença entre os términos apicais das obturações (exata ou subobturação) e os tipos de reparação periapical, parcial ou completa (Tabela 2).

\section{DISCUSSÃO}

O tratamento endodôntico em sessão única dos dentes com lesões periapicais ganhou popularidade a partir da Segunda Guerra Mundial, embora fosse seguido de cirurgia periapical ${ }^{33}$. Nas décadas seguintes, a Endodontia experimentou grande avanço tecnológico simplificando tecnicamente muitas etapas operatórias. Numa fase ascendente dessas inovações, MULHERN et al. ${ }^{14}$ (1982) e $\operatorname{OLIET}^{15}$ (1983) relataram que, independentemente do estágio patológico pulpar ou periapical, desde que os canais radiculares estivessem conicamente modelados, sem exsudação, o paciente assintomático e com tempo disponivel, poder-se-ía realizar a obturação definitiva. Tal filosofia foi posteriormente corroborada por outros estudos ${ }^{1,3,13,17,21,23,31-33}$.

Há inúmeras vantagens clínicas em realizar o tratamento endodôntico em sessão única ${ }^{4,13,14,15,32,33}$. No entanto, nenhum tratamento endodôntico deve limitar-se exclusivamente ao preenchimento de um espaço parcialmente modelado, principalmente quando há patologia periapical. Nesse sentido, SILVEIRA et l. $^{22}$ (1984/1985), indagando a endodontistas dos estados de São Paulo, Minas Gerais e Rio de Janeiro, certificaram que $91,17 \%$ acredi-
TABELA 2 - Tipos de reparação periapical e os respectivos términos apicais das obturações $(\mathrm{n}=28)$.

\begin{tabular}{l|c|c|c|c}
\hline \hline \multirow{2}{*}{$\begin{array}{c}\text { Nível apical das } \\
\text { obturações }\end{array}$} & \multicolumn{3}{|c|}{ Reparação } & \multirow{2}{*}{ Total } \\
\cline { 2 - 5 } & Completa & Parcial & Ausente & \\
\hline Exata & 4 & 5 & 1 & 10 \\
\hline Ligeiramente aquém & 9 & 8 & 1 & 18 \\
\hline Sobreobturação & - & - & - & - \\
\hline Total & 13 & 13 & 2 & 28 \\
\hline \hline
\end{tabular}

tam no fracasso do tratamento dos dentes com lesão periapical, quando realizado em sessão única. A experiência dos endodontistas americanos foi relatada por LANDERS; CALHOUN ${ }^{11}$ (1980), quando observaram que $91,4 \%$ dos coordenadores de pós-graduação preconizam o tratamento endodôntico de casos selecionados em sessão única, sendo mais freqüente para os dentes com polpa vital. Posteriormente, CALHOUN; LANDERS ${ }^{2}$ (1982) observaram que, dentre quatrocentos e vinte e nove especialistas americanos e professores de Endodontia, apenas $13,5 \%$ acreditavam no sucesso do tratamento em sessão única. Portanto, inúmeros endodontistas e educadores recomendam mais de uma sessão quando do tratamento endodôntico de dentes com necrose pulpar e envolvimento periapical, mesmo que após preparo biomecânico o canal radicular esteja clinicamente adequado à obturação.

A sintomatologia periapical pode resultar da interação de vários fatores. Por conseguinte, a infecção intracanal, proteínas pulpares quimicamente alteradas, o trauma da instrumentação, a citotoxicidade dos irrigantes e dos materiais obturadores associados a prévias experiências sintomáticas e ao estado psicológico do paciente são alguns dos potenciais elementos que podem alterar a sindrome de adaptação local, advindo os desagradáveis "flare-ups"20,29,30.

A microbiota endodôntica é elemento-chave na patogênese periapical e nas indesejáveis agudizações $^{5}$. Assim, SUNDQVIST et al. ${ }^{28}$ (1989) observaram formação de abscessos, quando da sobreinstrumentação em canais radiculares bastante infectados. Diferentemente da sobreinstrumentação, a extrusão periapical é inevitável, logo, todo tratamento endodôntico estaria, potencialmente, predestinado a causar dor. Não obstante, neste estudo os pacientes relataram baixa incidência de dor severa associada à inflamação ("flare-ups"), que foi da ordem de 3,3\%. Tal achado concorda 
SOARES, J. A.; CÉSAR, C. A. S. Avaliação clínica e radiográfica do tratamento endodôntico em sessão única de dentes com lesões periapicais crônicas. Pesqui Odontol Bras, v. 15, n. 2, p. 138-144, abr./jun. 2001.

com IMURA; ZUOLO ${ }^{10}$ (1995), cujo valor foi de $3,42 \%$. Por conseguinte, com atenção e cuidado, pode-se, durante o preparo biomecânico, evitar as sobreinstrumentações, bem como atenuar a extrusão de substâncias tóxicas no periápice, e independentemente da técnica de instrumentação, lograr reduzido desconforto pós-operatório ${ }^{4}$.

As sobreobturações podem determinar dor pós-operatória ${ }^{15,29}$. No presente estudo, embora não ocorresse sobreobturações, não se observou marcante associação entre o nível apical das obturações e a intensidade da dor, pois três pacientes sintomáticos com obturações exatas relataram dor leve, moderada ou severa e, em dois com obturação aquém, ocorreu dor tipo suave ou moderada. Também não se averiguou associação entre dor e condição microbiológica dos canais radiculares no momento da obturação, pois dos cinco pacientes sintomáticos, três estavam microbiologicamente positivos e dois com cultura negativa. Por conseguinte, dentre as variáveis locais analisadas, provavelmente, o preparo biomecânico atuou como principal responsável pela sintomatologia periapical. Essa hipótese é possível, uma vez que, em recente estudo, ao realizar tratamento endodôntico em pacientes com patologias periapicais, em várias sessões, SOARES ${ }^{25}$ (2001) registrou dor pós-operatória somente na primeira consulta, quando foi instituída a limpeza e modelagem dos canais radiculares.

No tocante à reparação periapical, aos 12 meses, apenas $46,4 \%$ das lesões estavam completamente reparadas e assintomáticas, ou seja, foram consideradas como sucesso, de acordo com ORSTAVIK $^{16}$ (1996) e SJÖGREN et al. ${ }^{23}$ (1997). Discordando de OLIET ${ }^{15}$ (1983) e COUTINHO FILHO et $a .^{3}$ (1997), dentes com lesões parcialmente reparadas, embora assintomáticos, foram classificados como insucesso. Se lesões parcialmente reparadas representassem tratamento bem-sucedido, terse-ía obtido $92,8 \%$ de sucesso clínico e radiográfico.

O preparo biomecânico é uma das fases mais importantes do tratamento endodôntico, conquanto sua efetividade anti-séptica é de caráter parcial e temporária ${ }^{24}$. Destarte, se o canal radicular permanecer vazio, mas selado coronariamente, num periodo de 48 a 96 horas ocorrerá proliferação dos microrganismos remanescentes. Assim, infere-se que a cultura microbiológica negativa proporcionada pelo mesmo não corresponde à esterilização do sistema de canais radiculares.

Todos os tratamentos endodônticos com completa resolução radiográfica periapical estavam microbiologicamente negativos, no momento da obturação. Entretanto, comparativamente, a ausência de microrganismos viáveis não foi, por si só, indicadora de sucesso, pois $85 \%$ das lesões parcialmente reparadas também apresentaram canais radiculares em similares condições.

Portanto, o ponto fundamental da questão são os critérios do que pode ser considerado sucesso ou insucesso, e tais aspectos são prováveis responsáveis pelas elevadas porcentagens de êxito, quando se realiza o tratamento endodôntico em sessão única ${ }^{1,3,15,17,21}$. Ademais, levando-se em conta que, muitas vezes, extensa destruição periapical escapa à acuidade do exame radiográfico periapi$\mathrm{Cal}^{18}$, e que lesões parcialmente reparadas podem corresponder à significativa alteração histopatológica $^{12}$, considerar a reparação parcial como sucesso merece a devida reflexão.

Por sua vez, o nivel apical das obturações, exata ou subobturação, não se correlacionou com o tipo de reparo periapical, parcial ou completo. No entanto, $70 \%$ das amostras completamente reparadas apresentaram obturações aquém do extremo apical radiográfico. Por ser a relação pó/líquido mais agressiva aos tecidos que o próprio nível da obturação ${ }^{7}$, no presente estudo estabeleceu-se uma proporção de $0,45 \mathrm{~g}$ de pó para 0,009 $\mathrm{ml}$ de líquido, o que assegura uma mistura com pouco eugenol residual e, conseqüentemente, menos citotóxica ao periápice.

As lesões periapicais estavam bem definidas radiograficamente, conforme ilustrado nas Figuras 1 e 2, embora com tamanhos variáveis. Contudo, não se averiguou diferença temporal no padrão de sua resolução, em função da dimensão inicial, mas a tendência de rápida involução, no intervalo de 6 a 8 meses. Possivelmente, esse comportamento radiográfico decorre da rápida deposição óssea nos locais mais distantes do ápice radicular, onde a reparação parece ser mais simplificada, por envolver apenas, tecido ósseo e vascular. Em contrapartida, à medida que se aproxima do ápice, a regeneração torna-se mais demorada, quer seja devido às características intrínsecas do cemento, ao processo de reestruturação do ligamento periodontal ou à presença de fatores estranhos: material obturador, raspas de dentina e infecção remanescente na região apical e nas circunvizinhanças do periápice $^{23,24}$. Em virtude desses possiveis fatos e eventos, a velocidade da reparação dependeria mais das condições do ápice radicular que do tamanho inicial da radiolucidez periapical.

O período de avaliação influencia nos resultados pós-operatórios. A limitação da proservação ao 
SOARES, J. A.; CÉSAR, C. A. S. Avaliação clínica e radiográfica do tratamento endodôntico em sessão única de dentes com lesões periapicais crônicas. Pesqui Odontol Bras, v. 15, n. 2, p. 138-144, abr./jun. 2001.
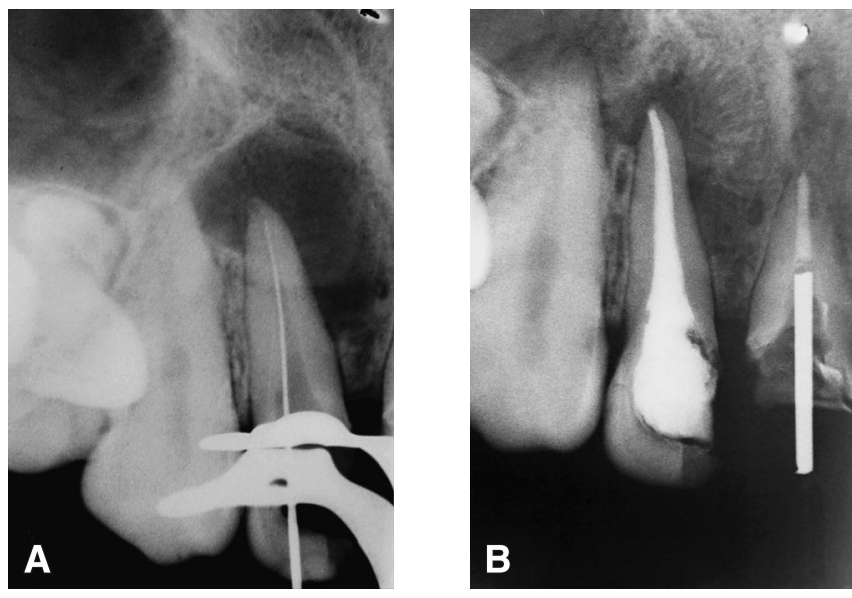

FIGURA 1 - A: radiografia de odontometria do dente 12 apresentando extenso processo osteolitico periapical. O canal radicular foi obturado mediante cultura microbiológica negativa; B: um ano após, verificou-se avançado processo reparativo periapical. Observa-se o término da obturação ligeiramente aquém do ápice radiográfico.

período de um ano deveu-se ao reduzido número de pacientes que compareceram às avaliações clínicas e radiográficas posteriores. Contudo, há estudos empregando períodos iguais ou inferiores $^{17,21,31}$. ORSTAVIK ${ }^{16}$ (1996) verificou maior incidência de sucesso no primeiro ano de proservação, declinando a partir de então. Portanto, a longo prazo, existe maior probabilidade das lesões repararem-se por completo, se bem que esse tempo seja indeterminado. Conseqüentemente, embora uma fração das radiolucidezes parcialmente reparadas, correspondam à escara periapical ${ }^{23}$, as lesões parcialmente reparadas serão melhor julgadas se avaliadas num maior intervalo de tempo.

De outra maneira, em vez de estender demasiadamente a proservação, uma alternativa mais promissora seria melhorar a anti-sepsia do sistema de canais radiculares e estimular a reparação periapical. Tal conduta fundamenta-se na aplicação de curativos de demora à base de hidróxido de cálcio, após o adequado preparo biomecânico, por períodos de 30 dias à vários meses. Em virtude da sua ionização e difusão, exercerá ação antimicrobiana ${ }^{24}$, inativação das endotoxinas ${ }^{19}$, e ativará, na região periapical, os mecanismos celulares e moleculares da regeneração tecidual $1^{6,8,9,12,19,24,26,27}$.

Com este procedimento, tem-se observado acentuada diminuição das áreas radiolúcidas periapicais, bem como completo reparo radiográfico periapical, em períodos de aproximadamente, 10 a 12 meses após a obturação dos canais radiculares $^{26}$. Destarte, estar-se-ia trocando anos de pro-
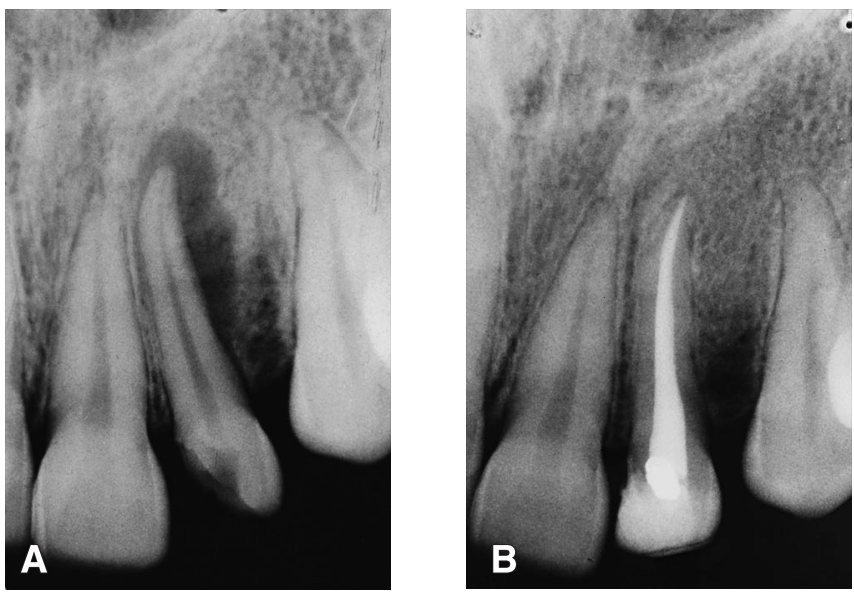

FIGURA 2 - A: na radiografia para diagnóstico, observa-se reabsorção óssea estendendo-se pelo aspecto apical e distal da raiz. Havia fistula por vestibular; B: dez dias após houve cicatrização da fístula. Decorridos 12 meses, observou-se completa reparação óssea periapical. Obteve-se cultura microbiológica negativa no momento da obturação.

servação por meses de medicação intracanal à base de hidróxido de cálcio em veículo hidrossolúvel. Julgamos esta alternativa altamente promissora e corrobora prévios estudos clínicos/radiográficos $^{6,27}$ e histopatológicos ${ }^{9,12,24}$, que caracteriza uma conduta conservadora e consciente, na resolução das patologias periapicais de origem endodôntica. Entretanto, como a medicação intracanal irá permanecer por um período superior a sete dias, é importante a restauração do dente com material definitivo, como por exemplo, resina. Isto reduzirá acentuadamente a microinfiltração coronária, a possibilidade de fratura da restauração provisória e até mesmo do dente, bem como a reinfecção do sistema de canais radiculares. O paciente deve ser esclarecido e se mostrar motivado para continuar com as trocas de medicamentos até o momento da obturação definitiva do dente.

\section{CONCLUSÕES}

1. Obteve-se reduzido percentual de dor pós-operatória do tipo severa, após o tratamento endodôntico concluído em sessão única.

2. A cultura microbiológica negativa, bem como a obturação exata ou ligeiramente aquém, não influenciaram significativamente o tipo de reparação periapical, parcial ou completa.

3. Aos doze meses todos os pacientes estavam assintomáticos, embora apenas $46,4 \%$ apresentassem completa resolução das áreas radiolúcidas periapicais. 
SOARES, J. A.; CÉSAR, C. A. S. Avaliação clínica e radiográfica do tratamento endodôntico em sessão única de dentes com lesões periapicais crônicas. Pesqui Odontol Bras, v. 15, n. 2, p. 138-144, abr./jun. 2001.

SOARES, J. A.; CÉSAR, C. A. S. Clinic and radiographic evaluation of one-appointment root canal therapy in teeth with chronic periapical lesions. Pesqui Odontol Bras, v. 15, n. 2, p. 138-144, abr./jun. 2001.

The aim of this study was to evaluate the incidence of postoperative pain and the type of periapical repair, after one-appointment endodontic treatment in asymptomatic patients who presented with pulpal necrosis and radiographically visible chronic periapical lesions. For that, after biomechanical preparation through the step down followed by the step back technique, aided by copious irrigation with $5.0 \%$ sodium hypochlorite solution, the filling of the root canals was carried out through the conventional technique, with gutta-percha cones and zinc oxide-eugenol cement. In the immediate postoperative period, $16.6 \%$ of all patients presented with spontaneous pain, although the incidence of severe pain - flare-ups - was 3.3\%. After twelve months, all patients were asymptomatic and free of fistula, nevertheless only $46.4 \%$ exhibited complete resolution of the radiolucent periapical areas. Therefore, in a medium term, the one-appointment endodontic treatment showed $100 \%$ of clinical success, but showed a reduced rate of radiographic success.

UNITERMS: Root canal therapy; Periapical diseases.

\section{REFERÊNCIAS BIBLIOGRÁFICAS}

1. BERGER, C. R. Tratamento endodôntico em sessão única ou múltipla. RGO, v. 39, n. 2, p. 93-97, mar./abr. 1991.

2. CALHOUN, R. L.; LANDERS, R. R. One-appointment endodontic therapy: a nationwide survey of endodontists. $\mathbf{J}$ Endod, v. 8, n. 1, p. 35-40, 1982.

3. COUTINHO FILHO, T.; GURGEL FILHO, E. D.; DIBLASI, F. Filosofia de trabalho nas obturações imediatas em dentes necrosados e com lesão apical. Rev Bras Odontol, v. 54, n. 5, p. 281-284, 1997.

4. FAVA, L. R. G. Single-visit root canal treatment: incidence of postoperative pain using three different instrumentation techniques. Int Endod J, v. 28, p. 103-107, 1995.

5. GOMES, B. P.; DRUCKER, D. B.; LILLEY, J. D. Association of endodontic symptoms and signs with particular combinations of specific bacteria. Int Endod J, v. 29, p. 69-75, 1996.

6. HEITHERSAY, G. S. Calcium hydroxide in the treatment of pulpless teeth with associated pathology. J Br Endod Soc, v. 8, p. 74-93, 1975.

7. HOLLAND, R.; SOUZA, V.; NERY, M. J. et al. Resposta do tecido conjuntivo subcutâneo do rato ao implante de alguns materiais obturadores de canal. Rev Fac Odont Araçatuba, v. 2, n. 2, p. 217-225, 1973.

8. HOLLAND, R.; VALLE, G. F.; TAINTOR, J. F. et al. Influence of bony resorption on endodontic treatment. Oral Surg Oral Med Oral Pathol, v. 55, p. 191-203, 1983.

9. HOLLAND, R.; SOUZA, V.; NERY, M. J. et al. Root canal treatment with calcium hydroxide: effect of an oily or a water soluble vehicle. Rev Odontol UNESP, v. 12, p. 1-6, 1983.

10. IMURA, N.; ZUOLO, M. L. Factors associated with endodontic flare-ups: a prospective study. Int Endod J, v. 28, p. 261-265, 1995.

11. LANDERS, R. R.; CALHOUN, R. L. One-appointment endodontic therapy: an opinion survey. J Endod, v. 6, n. 10, 1980.

12. LEONARDO, M. R.; ALMEIDA, W. A.; ITO, I. Y. et al. Radiographic and microbiologic evaluation of posttreatment apical and periapical repair of root canals of dog's teeth with experimentally induced chronic lesion. Oral Surg Oral Med Oral Pathol, v. 78, p. 232-238, 1994.
13. MOTTA, A. G. Incidência dolorosa após o tratamento endodôntico em uma sessão em dentes com polpa mortificada. Rev Bras Odontol, v. 54, n. 3, p. 150-152, 1997.

14. MULHERN, J. M.; PATTERSON, S. S.; NEWTON, C. W. et al. Incidence of postoperative pain after one-appointment endodontic treatment of asymptomatic pulpal necrosis in single-rooted teeth. J Endod, v. 8, p. 370-374, 1982.

15. OLIET, S. Single-visit endodontics: a clinical study. J Endod, v. 9, p. 147-152, 1983.

16. ORSTAVIK, D. Time course and risk analyses of the development and healing of chronic apical periodontitis in man. Int Endod J, v. 29, p. 150-155, 1996.

17. PEKRUHN, R. B. The incidence of failure following single-visit endodontic therapy. J Endod, v. 12, n. 2, p. 68-72, Feb, 1986.

18. PITT FORD, T. R. The effects on the periapical tissues of bacterial contamination of the filled root canal. Int Endod J, v. 15, p. 16-22, 1982.

19. SAFAVI, K. E.; NICHOLS, F. C. Effect of calcium hydroxide on bacterial lipopolysaccharide. J Endod, v. 19, p. 76-78, 1993.

20. SELTZER, S.; NAIDORF, I. J. Flare-ups in endodontics. I etiological factors. J Endod, v. 11, n. 11, p. 472-478, 1985.

21. SELTZER, S.; BENDER, I. B.; TURKENKOP, F. Factors affecting successful repair after root canal therapy. J Am Dent Assoc, v. 67, p. 51-62, 1963.

22. SILVEIRA, A. B.; MIRANDA NETTO, C. C.; MORAES, V. R. Tratamento endodôntico em sessão única: levantamento das opiniões dos endodontistas de Minas Gerais, Rio de Janeiro e São Paulo. Arqui Centro Estud Curso Odontol, v. 21/22, n. 2/1, p. 127-142, 1984/1985.

23. SJÖGREN, U.; FIDGOR, D.; PERSSON, S. et al. Influence of infection at the time of root filling on the outcome of endodontic treatment of teeth with apical periodontitis. Int Endod J, v. 30, p. 297-306, 1997.

24. SOARES, J. A. Estudo microbiológico dos canais radiculares, histopatológico e histobacteriológico dos tecidos apicais e periapicais, em função do preparo biomecânico e de dois curativos de demora à base de 
SOARES, J. A.; CÉSAR, C. A. S. Avaliação clínica e radiográfica do tratamento endodôntico em sessão única de dentes com lesões periapicais crônicas. Pesqui Odontol Bras, v. 15, n. 2, p. 138-144, abr./jun. 2001.

hidróxido de cálcio, utilizados em dois periodos de avaliação, no tratamento endodôntico de dentes de cães, com reação periapical crônica induzida. Araraquara, 1999. 455 p. Dissertação (Mestrado) - Faculdade de Odontologia, UNESP.

25. SOARES, J. A. Incidência de dor pós-operatória após tratamento endodôntico de dentes com áreas radiolúcidas periapicais, em uma ou múltiplas sessões. Rev Estomatol Fac Fed Odontol Diamantina, 2001. (no prelo).

26. SOARES, J. A. Tratamento conservador das patologias periapicais de origem endodôntica. Rev Estomatol Fac Fed Odontol Diamantina, 2001. (no prelo).

27. SOUZA, V.; BERNABÉ, P. F. E.; HOLLAND, R. et al. Tratamento não cirúrgico de dentes com lesões periapicais. RGO, v. 46, p. 39-46, 1989.

28. SUNDQVIST, G.; JOHANSSON, E.; SJÖGREN, U. Preva- lence of black-pigmented Bacteroides species in root canal infections. J Endod, v. 15, p. 3-19, 1989.

29. TORABINEJAD, M.; DORN, S. O.; ELEAZER, P. D. et al. Effectiveness of various medications on postoperative pain following complete instrumentation. J Endod, v. 20, p. 345-354, 1994.

30. TORABINEJAD, M.; KETTERING, J.; McGRAW, J. C. et al. Factors associated with endodontic interappointment emergencies of teeth with necrotic pulps. J Endod, v. 14, p. 261-266, 1988.

31. TROPE, M.; DELANO, E. O.; ORSTAVIK, D. Endodontic treatment of teeth with apical periodontitis: single $v$ s. multivisit treatment. J Endod, v. 25, p. 345-350, 1999.

32. WAHL, M. J. Mitos de uma cita endodôntica. J Endod Practice, v. 3, p. 33-38, 1997.

33. WOLCH, I. One-appointment endodontic treatment. J Can Dent Assoc, n. 11, p. 613-615, 1975.

Recebido para publicação em 22/06/00 Enviado para reformulação em 14/07/00 Aceito para publicação em 10/04/01 